\title{
IMPLEMENTASI SUPERVISI AKADEMIK PADA MADRASAH IBTIDAIYAH KABUPATEN TANAH DATAR
}

\author{
Syafruddin \\ Kepala MIN 1 Tanah Datar, Sumatera Barat \\ Korespondensi: Jln. Raya Batusangkar-Bukittinggi, Sungai Tarab \\ e-mail: syafruddin.939@yahoo.com
}

\begin{abstract}
The background in this research is the performance of teachers at Madrasah Ibtidaiyah in Tanah Datar District is still less than the maximum. Implementation of academic supervision at Madrasah Ibtidaiyah in Tanah Datar District, constrained by several things, including the plans made by the teachers are not in accordance with the implementation, time constraints supervisors and headmaster in carrying out supervision and there were some who did not complete the administrative requirements for learning devices. The purpose of researchers doing this study is to describe and analyze the academic supervision in the form of Madrasah Ibtidaiyah in Tanah Datar District and to describe and analyze the implementation of the academic supervision in the form of Madrasab Ibtidaiyah in Tanah Datar District.
\end{abstract}

Keywords: Implementation, Academic Supervision, Madrasah Ibtidaiyah

\section{PENDAHULAN}

Kualitas pendidikan sangat tergantung pada komponen-komponen yang terdapat dalam pendidikan, di antara komponen yang sangat mempengaruhi berhasil tidaknya pendidikan tergantung dari kualitas guru, dengan kata lain guru harus berkualitas. Salah satu upaya yang dapat dilakukan adalah dengan melakukan sebuah pengawasan atau supervisi. Untuk memahami supervisi pendidikan perlu memahami supervisi itu sendiri. Supervisi mempunyai arti pengawasan, dan orang yang melakukan supervisi disebut supervisor atau pengawas. Supervisor atau pengawas dianggap jabatan yang secara ideal diduduki oleh seseorang yang mempunyai keahlian di bidangnya. Kelebihan atau keunggulan bukan saja dari segi kedudukan, melainkan dari segi skill yang dimilikinya.

Menurut Mustofa, supervisi adalah pelayanan yang disediakan oleh pemimpin untuk membantu para guru agar menjadi guru yang berkualitas, cakap, dan terampil sesuai dengan perkembangan ilmu dan teknologi. Dengan demikian, supervisor dalam tugasnya meliputi perencanaan, tugas administrasi, melakukan partisipasi secara langsung dalam pengembangan kurikulum, melaksanakan demonstrasi mengajar untuk para guru, serta melaksanakan penelitian (Mustofa, 2013: 16).

Dalam Al Quran isyarat mengenai supervisi dapat diidentifikasi dari (salah satunya) ayat berikut (QS. Al-Hasyr: 18) 
"Hai orang-orang yang beriman, bertakwalah kepada Allah dan hendaklah Setiap diri memperhatikan apa yang telah diperbuatnya untuk hari esok (akhirat); dan bertakwalah kepada Allah, Sesungguhnya Allah Maha mengetahui apa yang kamu kerjakan".

Ayat di atas secara implisit mengungkapkan tentang urgensinya memperhatikan apa yang akan dikerjakan dan luasnya cakupan pengetahuan Allah SWT tentang segala sesuatu yang berkaitan dengan mahluk ciptaanya, dalam ayat tersebut juga mengisyaratkan posisi Allah SWT sebagai Pencipta merupakan pemilik otoritas tertinggi yang membawahi semua mahluk ciptaan-Nya, yang bila dikaitkan dengan konteks pengertian supervisi, yaitu supervisi dilakukan oleh atasan atau pimpinan yang tentunya memiliki otoritas yang lebih tinggi terhadap yang ada di bawahnya, atau bawahannya memiliki kesamaan konsep tentang subjek pelaku supervisi, yaitu samasama dilakukan oleh subjek yang memilki otoritas yang lebih tinggi terhadap subjek yang lebih rendah/bawahan.

Jadi, supervisi mempunyai pengertian yang luas. Supervisi adalah segala bantuan dari para pemimpin sekolah, yang tertuju pada perkembangan kepemimpinan guruguru dan personel sekolah lainnya di dalam mencapi tujuan-tujuan pendidikan. Ia berupa dorongan, bimbingan, dan kesempatan bagi pertumbuhan keahlian dan kecakapan guru-guru, seperti bimbingan dalam usaha dan pelaksanaan pembaharuan-pembaharuan dalam pendidikan dan pengajaran, pemilihan alat-alat pelajaran dan metode-metode mengajar yang lebih baik, cara-cara penilaian yang sistematis terhadap fase seluruh proses pengajaran, dan sebagainya. Dengan kata lain, supervisi ialah suatu aktivitas pembinaan yang direncanakan untuk membantu para guru dan pengawai sekolah lainnya dalam melakukan pekerjaan mereka secara efektif.

Pemerintah dalam kebijakan pendidikan nasional telah merumuskan kompetensi guru ada empat, hal tersebut tercantum dalam Penjelasan Peraturan Pemerintah No 19 Tahun 2005 tentang Standar Nasional Pendidikan, yaitu kompetensi pedagogik, kepribadian, profesional, dan sosial (Presiden Republik Indonesia, 2005).

Madrasah Ibtidaiyah Negeri (MIN) yang bernaung di bawah Kementerian Agama Republik Indonesia. Sebagai lembaga pendidikan dasar, MIN dianggap sebagai sekolah nomor dua atau bukanlah pilihan utama bagi para orang tua untuk menyekolahkan anak-anak mereka. Hal ini terjadi karena MIN dianggap kurang berkualitas dan kurang mampu menyelenggarakan pendidikan dasar dengan baik. Faktor dan kondisi ini diduga akan menjadi penyebab kurang berkualitasnya para lulusan Madrasah Ibtidaiyah Negeri.

Temuan khusus berdasarkan fenomena di lapangan, kinerja guru di MIN Kabupaten Tanah Datar masih kurang maksimal. Indikasinya adalah masih terdapat gejala-gejala kemangkiran dalam menjalankan aktivitas sebagai seorang pendidik pada lembaga pendidikan Islam, rendahnya semangat kerja, kurangnya motivasi yang diberikan oleh pimpinan sekolah, lingkungan tempat mengajar yang kurang kondusif serta keadaan siswa yang mempunyai latar belakang yang berbeda. Guru tidak hanya mengeluhkan faktor 
insentif yang dirasa rendah bagi mereka sehingga kurang memenuhi kebutuhan ekonomi yang semakin lama semakin meningkat, namun faktor lain seperti tempat kerja yang menjenuhkan. Suasana lingkungan kerja yang kurang kondusif seperti komunikasi antar guru yang kurang efektif, pimpinan sekolah yang kurang bijak serta siswa yang tingkah lakunya tidak sesuai dengan karakter siswa pada lembaga pendidikan Islam, juga menjadi keluhan para guru. Sebagian dari mereka, dalam pengamatan penulis, kelihatannya belum melaksanakan tugas dengan sungguhsungguh. Dikatakan demikian karena indikasi dari motivasi kerja guru yang masih rendah.

\section{SUPERMSI AKADEMK}

Supervisi adalah suatu layanan profesional berbentuk pemberian bantuan kepada personel sekolah dalam meningkatkan kemampuannya sehingga lebih mampu mempertahankan dan melakukan perubahan penyelenggaraan sekolah dalam rangka meningkatkan pencapaian tujuan sekolah, bahwa supervisi di dalam dunia pendidikan dapat dibedakan menjadi dua macam, yaitu supervisi umum dan supervisi pengajaran. Di samping kedua jenis supervisi tersebut kita mengenal pula istilah supervisi klinis (Bafadal, 2005: 72).

Langkah-langkah supervisi pendidikan dibagi dalam 5 langkah, yaitu, Pertama, menciptakan suasana kekeluargaan yang intim antara guru dengan supervisor agar komunikasi selama kegiatan dapat berlangsung secara efektif. Kedua, membuat kesepakatan antara guru dengan supervisor tentang aspek proses belajar-mengajar yang akan dikembangkan dan ditingkatkan, kedua perencanaan oleh guru dan supervisor yakni membuat perencanaan pelaksanaan observasi secara bersamaan. Ketiga, mengenai pelaksanaan pelatihan mengajar dan obsevasi yang mana guru sedang melakukan proses pembelajaran sedang supervisor melakukan pengamatan secara cermat, dengan menggunakan instrument observasi. Keempat, mengadakan analisis data, dalam hal ini supervisor mengajak guru untuk mendiskusikan apa yang telah dilaksanakan oleh guru melakukan proses pembelajaran di kelas. Kelima, langkah diskusi memberikan umpan balik yang bertujuan untuk memberikan umpan balik atas apa yang telah dilakukan oleh supervisor kepada guru yang sedang berlatih mengajar meningkatkan ketrampilannya dan pelaksanaan langkah pemberian umpan balik sebaiknya dilakukan secara obyektif dan segera. Secara umum tujuan supervisi adalah untuk mengembangkan dan mencapai proses belajar mengajar yang relevan dan efektif melalui peningkatan kemampuan guru (Sahertian, 1981: 20).

Supervisi tidak terjadi begitu saja. Oleh kerena itu, dalam setiap kegiatan supervisi terkandung maksud-maksud tertentu yang ingin dicapai dan hal itu terakumulasi dalam tujuan supervisi. Tujuan dapat berfungsi sebagai arah atau penuntun dalam melaksanakan supervisi, serta dapat sebagai tolok ukur dalam menilai efektiftidaknya pelaksanaan supervisi dan berkaitan erat dengan tujuan pendidikan di sekolah.

Pendekatan Supervisi terdiri dari (1). Pendekatan direktif. Di sini supervisor 
memberikan arahan langsung sehingga pengaruh perilaku supervisor lebih dominan. Karena itu supervisor harus benarbenar mempersiapkan diri dengan cara membekali ilmu pengetahuan yang berkaitan dengan kegiatan supervisi. Dengan tanggungjawabnya supervisor dapat melakukan perubahan perilaku mengajar dengan memberikan pengarahan yang jelas terhadap rencana kegiatan yang akan dievaluasi. (2). Pendekatan nondirektif. Di sini supervisor melakukan pendekatan terhadap masalah dengan cara tidak langsung. Pendekatan nondirektif ini berangkat dari premis bahwa belajar adalah pengalaman pribadi, sehingga pada akhirnya individu harus mampu memecahkan masalah sendiri. Pendekatan ini bercirikan perilaku di mana supervisor mendengarkan guru, mendorong guru, mengajukan pertanyaan, menawarkan pikiran bila diminta dan membimbing guru untuk melakukan tindakan. (3). Pendekatan kolaboratif, merupakan cara pendekatan yang memadukan cara pendekatan direktif dan nondirektif menjadi suatu cara pendekatan baru. Pada pendekatan ini baik supervisor maupun guru bersama-sama bersepakat untuk menetapkan struktur, proses dan criteria dalam melaksanakan proses percakapan terhadap masalah yang dihadapi guru.

Supervisi Akademik adalah proses membantu guru dalam mengembangkan kemampuannya mengelola proses pembelajaran untuk mencapai tujuan pembelajarannya yang dilakukan oleh pengawas dan kepala sekolah. Suprvisi akademik hampir sama dengan supervisi pembelajaran. Jika supervisi pembelajaran fokusnya pada proses pambelajaran guru, maka supervisi akademik sifatnya lebih kompleks, dikatakan kompleks karena tidak hanya pembelajaran saja, tapi juga menyantuh kurikulum, penelitian, klompok kerja guru,dan lain sebagainya.

Supervisi Akademik yang baik adalah supervisi yang mampu berfungsi untuk mencapai multitujuan tersebut di atas. Tidak ada keberhasilan bagi Supervisi Akademik jika hanya memerhatikan salah satu tujuan tertentu dengan mengesampingkan tujuan yang lainnya. Apabila tujuan-tujuan tersebut sudah diaplikasikan dengan baik tentunya supervisi akademik akan berfungsi mengubah perilaku mengajar guru. Pada gilirannya nanti perubahan guru ke arah yang berkualitas akan menimbulkan perilaku belajar murid yang lebih baik.

\section{SUPERYSOR}

Pelaku supervisi bukan lagi hanya pengawas dan kepala sekolah tetapi beberpa pihak terkait dengan kegiatan pembelajaran diantaranya, (1). Pengawas, Pengawas adalah penanggung jawab utama atas terjadinya pembinaan sekolah sesuai dengan jenis dan jenjang lembaga pendidikannya. (2). Kepala Sekolah, Kepala sekolah sebagai supervisor, setiap hari dia dapat secara langsung melihat dan menyaksikan kejadian, bahkan dengan langsung pula dapat memberikan pembinaan untuk peningkatan. (3). Wakil Kepala Sekolah Bidang Kurikulum, Tugas Wakasek Bidang Kurikulum ini adalah mengurusi semua urusan yang berkaitan dengan kurikulum dan pembelajaran. (4). Wakil Kepala Sekolah Bidang Kesiswaan. Wakasek bidang kesiswaan adalah pejabat yang dapat dikatakan paling akrab dengan 
seluruh kehidupan siswa. Dengan kedudukan itu yang bersangkutan dapat elakukan upaya pembinaan secara intensif, baik berdasarkan data yang diperolehnya sendiri maupun "titipan" dari pihak lain, misalnya kepala sekolah dan guru-guru. (5). Wali Kelas, Wali kelas adalah personil yang bertanggung jawab atas kemajuan siswa di kelas tertentu. Dengan kedudukannya itu wali kelas tentunya memiliki data yang lengkap tentang keadaan siswa yang terdaftar di kelas bersangkutan. (6). Petugas Bimbingan dan Konseling, dalam kegiatan supervisi sekolah ini petugas bimbingan dan konseling diberdayakan dan dihidupkan fungsinya sebagai pelaksana bimbingan studi, yaitu mengolah data tentang hal-hal yang snagat berkaitan dengan upaya meningkakan prestasi belajar siswa. (7). Petugas Perpustakaan, petugas perpustakaan sebagai orang yang telah ditunjuk dan diserahi tanggung jawab pengelola perpustakaan dapat membantu peningkatan prestasi siswa melalui pemanfaatan bahan koleksi perpustakaan (Sahertian, 1981: 131143).

Berdasarkan uraian tersebut, tampak bahwa supervisor mempunyai fungsi yang sangat penting dalam upayanya membantu untuk meningkatkan kualitas baik proses maupun hasil pembelajaran di sekolah. Sehubungan dengan hal tersebut, Depdiknas (1994) dalam Banun merumuskan tugas supervisor meliputi; (1) peningkatan kemampuan guru mengelola kegiatan belajar-mengajar; (2) memperbaiki dan meningkatkan sikap profesional guru yang berkaitan dengan kemampuan mengelola kegiatan belajar-mengajar. Di samping itu, terdapat pula tugas-tugas yang wajib dilaksanakan oleh seorang supervisor, yaitu; (1) tugas pengendalian; (2) tugas sebagai sponsor; (3) tugas sebagai evaluator; (4) tugas sebagai pengawas.

Tugas kepala sekolah sebagai supervisor adalah bahwa dia hendaknya pandai meneliti, mencari, dan menentukan syarat-syarat mana sajakah yang diperlukan bagi kemajuan sekolahnya sehingga tujuantujuan pendidikan di sekolah itu semaksimal mungkin dapat tercapai. Ia harus dapat meneliti dan menentukan syarat-syarat mana yang telah ada dan mencukupi, mana yang belum ada atau kurang mencukupi yang perlu diusahakan dan dipenuhi (Purwanto, 1990: 74).

Model-model supervisi adala sebagai berikut, yaitu: (1). Model supervisi konvensional. Supervisor mengadakan inspeksi untuk mencari serta menemukan kesalahan. Kadang model ini bersifat memata-matai dan menggurui. (2). Model Supervisi yang bersifat ilmiah. Supervisi ini dilaksanakan secara berencana, kontinu, sistematis, dengan menggunakan menggunakan prosedur dan teknik tertentu, serta instrumen pengumpulan data, sehingga memperoleh data yang objektif dari keadaan yang sebenarnya. (3). Model supervisi klinis, merupakan suatu proses bimbingan dalam pendidikan yang bertujuan membantu pengembangan profesional guru khususnya dalam penampilan mengajar, berdasarkan observasi dan analisis data secara teliti dan objektif sebagai pegangan untuk perbaikan tingkah laku mengajar guru. (4). Model supervisi artistik, memandang bahwa mengajar adalah suatu pengetahuan (knowledge), mengajar itu suatu keterampilan (skill), tetapi mengajar juga suatu kiat (art). 
Demikian juga dengan supervisi, yang merupakan suatu pengetahuan, suatu keterampilan dan juga suatu kiat (artistik).

\section{METODE PENEUTAN}

Peneltian ini adalah bersifat kualitatif, dengan menggunakan metode penelitian etnografi. Kata etnografi berasal dari katakata Yunani "ethos" yang artinya suku bangsa dan graphos yang artinya sesuatu yang ditulis. Menurut Emzir (2012: 18) etnografi adalah ilmu penulisan tentang suku bangsa, menggunakan bahasa yang lebih kontemporer, Etnografi dapat diartikan sebagai penulisan tentang kelompok budaya. Menurut Ary, dkk (2010:459) etnografi adalah studi mendalam tentang perilaku alami dalam sebuah budaya atau seluruh kelompok sosial. Pemilihan sumber data tidak berdasarkan kedekatan emosional, partner, dan lain-lainnya yang dapat memengaruhi objektivitas dari perolehan data, akan tetapi adalah murni karena sesuai dengan kepentingan permasalahan dan tujuan penelitian.

Instrumen penelitian yang digunakan peneliti dalam penelitian ini adalah sebagai berikut:

\section{Observasi}

Dalam melakukan observasi penulis menggunakan alat berupa fhoto digital, perakam video dan buku untuk menuliskan hal-hal yang didapati langsung yang berhubungan dengan implementasi supervisi akademik pada Madrasah Ibtidaiyah Kabupaten Tanah Datar.
2. Wawancara

Dalam melakukan wawancara penulis menggunakan alat berupa:

a. Pedoman wawancara yang menguraikan poin-poin khusus yang penting yang didiskusikan dengan informan, yaitu guru, siswa dan karyawan pada Madrasah Ibtidaiyah Kabupaten Tanah Datar.

b. Buku catatan berfungsi untuk mencatat semua percakapan dengan informan.

c. Kamera berfungsi untuk memotret peneliti pada saat melakukan wawancara sehingga dapat dimafaatkan sebagai bukti penelitian, dan alat-alat lain yang dirasakan perlu.

\section{Studi Dokumentasi}

Dalam melakukan studi dokumentasi peneliti mengklasifikasikan dukumenn ke dalam 2 jenis, yaitu:

a. Soft copy, yaitu dokumen yang peneliti dapat dari tempat penyimpanan data seperti komputer dan laptop yang ada di Madrasah Ibtidaiyah Kabupaten Tanah Datar.

b. Hard copy, yaitu dokumentasi pada Madrasah Ibtidaiyah Kabupaten Tanah Datar yang ada didalam file penyimpanan dukumentasi, seperti laporan kegiatan sekolah dan fotofoto kegiatan sekolah.

\section{HASIL PENEUTIANDANPEMBEHASAN}

Berdasarkan temuan yang dikemukakan, dapat dikemukakan beberapa hasil penelitian, yaitu: 
1. Bentuk Supervisi Akademik Pada Madrasah Ibtidaiyah Kabupaten Tanah Datar

Supervisi Akademik yang dilakukan di Madrasah Ibtidaiyah Tanah Datar adalah meliputi perencanaan, tugas administrasi, melakukan partisipasi secara langsung dalam pengembangan kurikulum, melaksanakan demonstrasi mengajar untuk para guru, serta melaksanakan penelitian. Adapun bentuk supervisi di Madrasah Ibtidaiyah Tanah Datar adalah sebagai berikut:

a. Supervisi Pengajaran yaitu pelaksanaan supervisinya dengan sederhana

b. Supervisi Klinis yaitu pelaksanaan supervisinya dengan membuat jadwal sampai kepada evaluasi dari hasil pelaksanaan supervisi.

2. Bentuk Pelaksanaan Supervisi Akademik Pada Madrasah Ibtidaiyah Kabupaten Tanah Datar

a. Pelaksanaan Supervisi Pengajaran di Madrasah Ibtidaiyah Tanah Datar:

1) Menginstruksikan kepada para guru agar melakukan persiapan sebelum supervisi di mulai.

2) Dengan cara memperbaiki perangkat pembelajarannya para guru tersebut, agar mereka lebih memahami lagi dan dan dapat mendalami materi pada bidang studi yang diajarkannya kepada para siswanya.

3) Mengupayakan untuk menyediakan kebutuhan yang memadai sesuai dengan keperluan seperti peraalatan dan media yang mendukung proses pembelajaran, dan pbahan yang lainya yang dirasakan perlu.
4) Kelengkapan adminstrasi kelas dan administrasi pembelajaran yang berhubungan dengan perangkat pembelajaran

b. Pelaksanaan Supervisi Klinis di Madrasah Ibtidaiyah Tanah Datar, yaitu dengan cara:

1) Perencanaan Supervisi

a) Mengkaji ulang tentang konsep supervise tersebut

b) Memusyawarahkan dengan wakil bidang kurikulum dalam penyusunan jadwal supervisi.

c) Menyusun program penilaian tentang supervisi tersebut berdasarkan kesepakatan dengan guru bidang studi.

d) Menginformasikan kepada guru agar mempersiapkan diri serta bahan-bahan yang diperlukan pada saat supervisi, yang menyangkut perangkat-perangkat pembelajaran seperti Rincian Minggu Efektif, PROTA, PROSEM, Silabus, KKM, dan RPP serta untuk memahami langkah-langkah penilaian yang telah disepakati.

2) Observasi ke dalam Kelas

a) Memberitahukan kepada guru tentang jadwal yang akan di supervisi pada saat itu.

b) Mengecek kembali semua perangkat pembelajaran yang disiapkan oleh guru.

c) Memberikan penilaian tentang sikap mengajar guru tersebut mulai dari awal mengajar sampai akhir dia mengajar. 
3) Evaluasi

a) Memusyawarkan dengan guru tentang hasil penilaian

b) Memberikan bimbingan berupa, arahan, masukan, dan pembinaan terhadap guru yang disupervisi sesuai dengan perangkat pembelajaran dan aspek penilaian yang telah disepakati tersebut.

c) Mencari solusi tentang kesulitan yang dihadapi guru dalam proses pembelajaran.

\section{KESIMPULAN}

Bentuk supervisi di Madrasah Ibtidaiyah Tanah Datar adalah supervisi pengajaran yaitu pelaksanaan supervisinya dengan sederhana dan supervisi klinis yaitu pelaksanaan supervisinya dengan membuat jadwal sampai kepada evaluasi dari hasil pelaksanaan supervisi. Pelaksanaan Supervisi Akademik Pada Madrasah Ibtidaiyah Kabupaten Tanah Datar yang terdiri dari supervisi pengajaran dan supervisi klinis terlaksana dengan baik.

\section{KEPUSTAKAANACUAN}

Aris Budiman, Desain Penelitian, Pendekatan Kualitatif \& Kuantitatif, (Jakarta: KIKI Press, 2002)

Ary, Donald., Jacobs, Lucy Cheser., Razavieh, Asghar. Introduction to Research in Education 8th edition. Wardswoth Cengage Learning. (Canada: Nelson Education ltd, 2010)

Asri Budiningsih, Belajar dan Pembelajaran, (Jakarta: PT Rineka Cipta, 2005)
Cresswell, Jhon W., Eduactional Research: Planning, Conducting, and Evaluating Quantitative and Qualitative Research. (Ney Jersey: Person Education, Inc, 2012)

Dadang Suhardan, Supervisi Profesional, Layanan dalam Meningkatkan Mutu Pembelajaran di Era Otonomi Daerah, (Bandung: Alfabeta, 2010)

Davis, K. Perilaku Dalam Organisasi. (Jakarta: Erlangga, Edisi Ketujuh. 1990)

Emzir. Metodologi Penelitian Kualitatif: Analisis Data. (Jakarta: Rajawali Pers, 2012)

Glickman, C.D., Gordon, S.P., and RossGordon, J.M. Supervisionand Instructional Leadership A Development Approach. Seventh Edition. (Boston: Perason, 2007)

Guru Kelas V, MIN Sungai Tarab, Wawancara Pribadi, Batusangkar: 13 Juni 2016,

Guntur Setiawan, Implementasi Dalam Birokrasi Pembangunan, (Bandung: Remaja Rosdakarya Offset2004)

Hadari Nawawi, Penelitian Terapan, (Yogyakarta: Gajah Mada Universitas Press, 1996)

http://id.wikipedia.org/wiki/Kabupaten_T anah_Datar

http://khairuddinhsb.wordpress.com/2008 /10/19/supervisi-pendidikan/, http://khairuddinhsb.wordpress.com /2008/10/19/supervisi-pendidikan/,

http://khairuddinhsb.wordpress.com/2008 /10/19/syarat-supervisorpendidikan, 
Husaini, Usman, Metodologi Penelitian Sosial, (Jakarta: Bumi Aksara, 2003)

Ibrahim Bafadal, Dasar-dasar Manajemen dan Supervisi Taman Kanak-kanak, (Jakarta: Bumi Aksara, 2005)

Imran, Pengawas Pendidikan MI Kabupaten Tanah Datar, Wawancara Pribadi, Batusangkar: 16 Juni 2016

Jasmani Asf dan Syaiful Mustofa, Supervisi Pendidikan, (Yogyakarta: Ar-Ruzz Media, 2013)

Kartini, Kartono, Pengantar Metodologi Riset Sosial, (Bandung: Mandar Maju, 1990)

Kepala Sekolah MIS Batusangkar, Wawancara Pribadi, Batusangkar: 16 Juni 2016

Lexy J. Moleong, Metodologi Penelitian Kualitatif, (Bandung: Remaja Rosdakarya, 2002)

Luk-Luk Nur Mufidah, Supervisi Pendidikan, (Jember: CSS, 2008)

M. Burhan Bungin, Penelitian Kualitatif; Komunikasi, Ekonomi, Kebijakan Publike, dan Ilmu Sosial Lainnya, (Jakarta: Kencana, 2008)

M. Ngalim Purwanto, Administrasi dan Supervisi Pendidikan, (Bandung: PT Remaja Rosdakarya, 1990)

Made Pidarta, Supervisi Pendidikan Kontekstual, (Jakarta: Rineka Cipta, 2009)

Mathis R.L dan Jackson J.H, Manajemen Sumber Daya Manusia, (Salemba Empat, Jakarta. 2002)
Michail Quin Patton, Qualitatif Evaluation and Research Method, (Newbury Park: Sage Publication, 1990)

Muwahid Shulhan, Administrasi Pendidikan, (Jakarta: Bina Ilmu, 2004)

Nurdin Usman, Konteks Implementasi Berbasis Kurikulum, (Jakarta:PT. Raja Grafindo Persada. 2002)

Nadhirin, Supervisi Pendidikan Interatif Berbasis Budaya, (Yogyakarta: Idea Press Yogyakarta, 2009)

Oemar Hamalik, Manajemen Pengembangan Kurikulum, (Bandung: Remaja Rosdakarya, 2008)

Piet A. Sahertian, Konsep Dasar \& Teknik Supervisi Pendidikan dalam Rangka Pengembangan Sumber Daya Manusia, (Jakarta: Rineka Cipta, 2000)

Piet A. Sahertian, Prinsip dan Tehnik Supervisi Pendidikan, (Surabaya: Usaha Nasional, 1986)

Piet. A. Sahertian, Prinsip dan Tehnik Supervisi, (Surabaya: Usaha Nasional, 1981)

Ramayulis, Metodologi Pendidikan Agama Islam, cet. ke-4, (Jakarta: Kalam Mulia, 2005)

Ratan Amir, Kepala sekolah MIM Batu Taba, Wawancara Pribadi, Batusangkar: 14 Juni 2016

Ridwan, Metode dan Teknik. Menyusun Skripsi, (Bandung: Al-Fabeta, 2004)

Sri Banun Muslim, Supervisi Pendidikan Meningkatkan Kualitas Profesionalisme Guru, (Bandung: Alfabeta, 2009) 
Sugiyono, Memahami Penelitian Kualitatif, Syaiful Sagala, Kemampuan Profesional Guru (Bandung: ALFABETA, 2005) dan Tenaga Kependidikan, (Bandung: Suharsimi Arikunto dan Lia Yuliana, Alfabeta, 2009)

Manajemen Pendidikan, (Yogyakarta: Zainal Aqib dan Elham Rohmanto, Aditya Media, 2008)

Suharsimi Arikunto, Dasar-dasar Supervisi, Buku Pegangan Kuliah, (Jakarta: Rineka Membangun Profesionalisme Guru dan Pengawas Sekolah, (Bandung: Yrama Widya, 2008). Cipta, 2004). 